\title{
Quantitative developmental response to the length of exposure to long photoperiod in wheat and barley
}

\author{
D. J. MIRALLES ${ }^{1 *}$, G. A. SLAFER ${ }^{1,2} \dagger$, R. A. RICHARDS ${ }^{3}$ AND H. M. RAWSON ${ }^{3}$ \\ ${ }^{1}$ Departamento de Producción Vegetal, Facultad de Agronomía, Universidad de Buenos Aires, \\ Av. San Martín 4453 (1417) Buenos Aires, Argentina \\ ${ }^{2}$ IFEVA, Universidad de Buenos Aires, Av. San Martín 4453 (1417) Buenos Aires, Argentina \\ ${ }^{3}$ Division of Plant Industry, CSIRO, G.P.O. Box 1600, Canberra, A.C.T. 2601, Australia
}

(Revised MS received 31 July 2003)

\begin{abstract}
SUMMARY
The present study was designed to analyse the effect of the length of exposure to a long photoperiod imposed $c .3$ weeks after sowing in spring wheat ( $c v$. UQ189) and barley ( $c v$. Arapiles) to (i) establish whether the response to the number of cycles of exposure is quantitative or qualitative, (ii) determine the existence of a commitment to particular stages well before the stage has been observable, and (iii) study the interrelationships between the effects on final leaf number and phyllochron when the stimulus is provided several days after seedling emergence. Both wheat and barley seemed to respond quantitatively to the number of long-day cycles they were exposed to. However, wheat showed a requirement of approximately 4 long-day cycles to be able to produce a significant response in time to heading. The barley cultivar used in the study was responsive to the minimum length of exposure. The response to extended photoperiod cycles during the stem elongation phase was due to the 'memory' photoperiod effects being related, in the case of wheat, to the fact that the pre-terminal spikelet appearance phase saturated its photoperiod response well before that stage was reached. Therefore, the commitment to the terminal spikelet appearance in wheat may be reached well before this stage could be recognized.

As the response in duration to heading exceeded that of the final leaf number, and the stem elongation phase responded to memory effects of photoperiod, the phyllochron of both cereals was responsive to the treatments accelerating the average phyllochron when exposed to longer periods of long days. The response in average phyllochron was due to a switch from bi-linear to linear models of leaf number $v$. time when the conditions were increasingly inductive, with the phyllochron of the initial (6-8) leaves being similar for all treatments (within each species), and from then on increased.
\end{abstract}

\section{INTRODUCTION}

Temperate cereals such as wheat and barley can respond to increased photoperiod by increasing the rate of phenological development thereby reaching ear emergence in less time (Allison \& Daynard 1976). While wheat can respond to photoperiod immediately after seedling emergence (Hay \& Kirby 1991; Slafer \& Rawson 1995), it seems that photoperiod responsiveness in at least some cultivars of barley only occurs

\footnotetext{
* To whom all correspondence should be addressed. Email: miralles@agro.uba.ar

$\uparrow$ Current address: Crop Protection and Forestry, University of Lleida, Centre Ud-IRTA, Av. Rovira Roure 191, 25198 Lleida, Spain.
}

beyond a basic juvenile phase (Ellis et al. 1992). In any case, it has been commonly assumed that photoperiod loses its influence with the advancement of development (Porter \& Delecolle 1988; Kirby 1991; Slafer \& Rawson 1994). Thus, plants are very sensitive at the beginning of the growing season and that is the stimulus to which their development responds, implying little or no influence in other phases independently of what has been sensed in the earliest periods. At least in part, this view may be based on results from field experiments with different sowing dates (Hay 1986) and supported by the fact that simulation models with sensitivity to photoperiod as described above effectively predict the phenology of field-grown temperate cereals in most situations 
(Ritchie 1991). However, sowing-date experiments are not suited for testing whether sensitivity is reduced, maintained, or even increased throughout development, as the later the phase under consideration the more uniform the environmental conditions (see detailed discussion in Slafer \& Rawson 1994). In fact, several authors have shown that photoperiod has an important influence during spikelet initiation (Rawson 1970; Rahman \& Wilson 1977), or even later during the stem elongation phase (Slafer \& Rawson 1996; Kernich et al. 1997; Miralles \& Richards 2000). Photoperiod sensitivity during different phases, independent of the sensitivity of previous phases, might be a relevant tool in future breeding for altering the duration of phenological phases (Fischer 1996; Slafer et al. 1996; Miralles et al. 2000; Slafer et al. 2001).

Slafer \& Rawson (1994) suggested that the previous, as well as the current, environment affects development. In addition, Slafer \& Rawson (1995) demonstrated that responses to photoperiod were not limited to the period during which the stimulus was applied, indicating that plants are committed to a developmental pattern well before a particular developmental stage could be identified. The perception of photoperiod from the timing of commitment to the identification of the developmental stage is then manifested as a 'memory' effect on the length of the successive phase. Thus, the commitment of a particular developmental event throughout crop ontogeny might be determined by the accumulation of promoting stimuli during previous phases.

Although the literature is full of examples of the quantitative response of cereals to the length of the photoperiod when the treatments are imposed continuously, little information is available in relation to whether the development in temperate cereals is quantitatively responsive to the length of the exposure to inductive photoperiods, which would be required for the accumulation of the stimulus. If this is the case, a realistic model on the physiological responses of wheat and barley to photoperiod must include a continuous perception of the stimulus as well as the capacity to react well beyond the timing when the final leaf number is determined. This would require not only that phyllochron is sensitive to photoperiod but also that it senses photoperiod later than at seedling emergence.

The present work therefore studied the effect of the length of exposure to a long photoperiod imposed c. 3 weeks after sowing in wheat and barley in order to (i) establish whether the response to the number of cycles of exposure is quantitative or qualitative, (ii) determine the existence of a commitment to particular stages well before the stage has been observable and (iii) study the interrelationships between the effects on final leaf number and phyllochron when the stimulus is provided several days after seedling emergence.

\section{MATERIALS AND METHODS}

A phytotron study was conducted in naturally lit temperature- and photoperiod-regulated growth cabinets at CSIRO (Canberra). Cabinets were naturally lit for $9 \mathrm{~h}$ (between 08.00 and $17.00 \mathrm{~h}$ ). Barley and wheat seeds were sown in $100 \times 150 \mathrm{~mm}$ pots; on 8 January and 16 February 1998, respectively, at a rate of two seeds per pot filled with a mixture of $50 \%$ perlite and $50 \%$ vermiculite.

Mean temperature in the growth cabinets was $13{ }^{\circ} \mathrm{C}$, achieved as a sinusoidal daily cycle between extremes of 17 (day) and $9{ }^{\circ} \mathrm{C}$ (night). Plants were supplied with complete Hoagland's nutrient solution each morning and with water each afternoon.

The study comprised 18 treatments given by the factorial combination of two genotypes and nine photoperiod regimes. Genotypes consisted of a semidwarf bread wheat (Triticum aestivum L.), $c v$. UQ189 and a two-rowed barley (Hordeum vulgare L.), $c v$. Arapiles. These cultivars were chosen as both possess strong photoperiod sensitivity but are virtually insensitive to vernalization (Stapper \& Fischer 1990; R. Flood, personal communication).

The imposition of the photoperiod treatments started 12 and 15 days after seedling emergence in wheat and barley, respectively. After sowing, the pots were maintained at the short photoperiod $(9 \mathrm{~h})$ until the beginning of the treatments. Similarly, at the end of the treatment period pots were maintained in the short photoperiod. The photoperiod treatments (Fig. 1) consisted of exposure of plants to 0, 2, 4, $8,10,12,14,18$ or 22 continuous days of long photoperiod $(19 \mathrm{~h})$. The long photoperiod treatment was achieved by extending the short photoperiod treatment with low intensity $\left(c .10 \mu \mathrm{mol} / \mathrm{m}^{2}\right.$ per $\mathrm{s}$ PAR) incandescent lamps. Pots were regrouped each week to homogenize light penetration and prevent edge effects.

Plants subjected to long photoperiod treatments were replicated in three separate growth cabinets: each block consisted of a cabinet. Treatments were then arranged in a split plot design, with photoperiod regimes as main plots and the two species as subplots.

From seedling emergence to heading, the development stages of main stems of individual randomly selected plants were regularly monitored to determine the duration of different phenological phases. Three plants per treatment were sampled every 3 days from seedling emergence onwards. These plants were dissected and the number of primordia recorded. The final number of spikelets at the terminal spikelet appearance stage in wheat and the maximum number of spikelet primordia at the awn initiation stage in barley were estimated. The timing of cessation of the leaf initiation phase (collar) was estimated by interpolation as the time when the number of primordia 


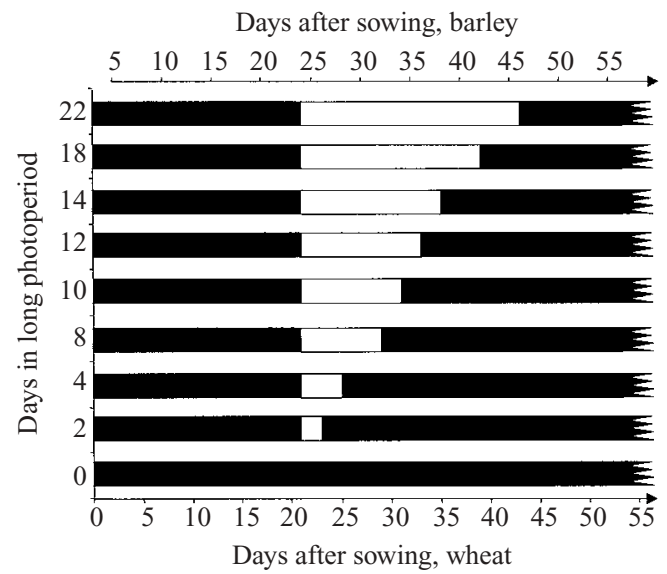

Fig. 1. Diagram of the photoperiod treatments. All treatments received $9 \mathrm{~h}$ of natural radiation (closed bars) with the photoperiod being extended by $10 \mathrm{~h}$ (open bars) producing the long photoperiod $(19 \mathrm{~h})$ treatment for the number of days indicated, thereafter grown under the short $(9 \mathrm{~h})$ photoperiod until heading. Note that the axis for barley is displaced 3 days to the left (i.e. treatments were imposed 3 days after sowing later in barley than in wheat).

initiated in the apex exceeded by one the final number of leaves emerged on the main shoots. Then the initiation of the collar represents the actual switch from vegetative to reproductive development.

In each replicate, three plants per experimental unit were tagged at seedling emergence to determine the dynamics of leaf emergence. In these plants, the number of emerged leaves on the main stem was determined following the method developed by Haun (1973) every 2 days. The final number of leaves produced in the main shoot of these plants was also recorded.

Rate of leaf emergence was estimated as the slope of the regression between the accumulated number of emerged leaves on the main stem and time. Linear or bi-linear models using optimization techniques were used to fit the relationship between both variables depending on the distribution of residuals (for details see Miralles \& Richards 2000). The phyllochron was calculated as the reciprocal of the rate of leaf emergence. Regression analyses were also used to estimate the relationship between variables. In both species the relationship between duration of sowing-heading phase and number of long days was fitted by a linear model. Whenever a linear fit did not produce a random distribution of residuals (as in wheat) a broken stick regression model was employed using optimization techniques. The estimates of parameters of a trilinear model (Eqn 1) were continuously improved by fitting least squares until the iterative procedure did not give a better fit. The segmented function used in wheat was:

$$
\begin{aligned}
Y= & a+b x(x \leqslant c)+b c(x>c) \\
& +d(x-c)(x>c)(x<e)+d(e-c)(x \geqslant e)
\end{aligned}
$$

where $Y$ is the duration from sowing to heading (days), $a$ the intercept, $b$ the rate of reduction in duration of the phase by increases on the number of long days $(x)$ between 0 days and the first inflection point (parameter $c$ ), $d$ the maximum rate of reduction in duration of the phase between first inflection point and when no further reductions were detected (parameter $e$ ).

\section{RESULTS}

Although wheat and barley had similar general trends, they differed slightly in the minimum number of long-day cycles required to produce a response, and to saturate it.

Both species showed a quantitative response to the accumulation of long-day cycles, with time to heading being consistently reduced as exposure to the number of long-days increased. While barley exhibited a clear reduction in time to heading from the shortest exposure, wheat seemed to require at least $c .3 \pm 0 \cdot 47$ (value and standard error of parameter $c$ of Eqn 1) long-day cycles before the plant responded as the first slope was not significantly different from 0 (Fig. 2). Both species also differed in that UQ189 appeared to have saturated its response with $c$. 18 long days, as value of parameter $e$ in Eqn 1 was $17 \cdot 6 \pm 0 \cdot 50$, while Arapiles did not exhibit any sign of saturation (Fig. 2).

UQ189 wheat and Arapiles barley were studied to determine if they were sensitive to photoperiod before and after the achievement of maximum primordial number. The sowing to heading period was partitioned into (i) the period from sowing to the appearance of terminal spikelet in wheat and the appearance of awn primordia in barley and (ii) the duration from the end of (i) to heading (i.e. the stem elongation phase). Both UQ189 wheat and Arapiles barley were sensitive to photoperiod during both periods if the number of long-day cycles were sufficient. Figure 3 shows the response relative to the short-day controls. Interestingly, the response of the stem elongation phase tended to commence at a length of exposure that saturated the response of the previous phase from sowing to the onset of stem elongation. This is very clear in the case of UQ189 wheat (Fig. 3).

The onset of stem elongation in the 22 long-days exposure treatment occurred 2 days after the wheat had been returned to short days, whereas in Arapiles barley, stem elongation began 3 days after the return to short days. In other words, all the responses to exposure to long photoperiod of the stem elongation 


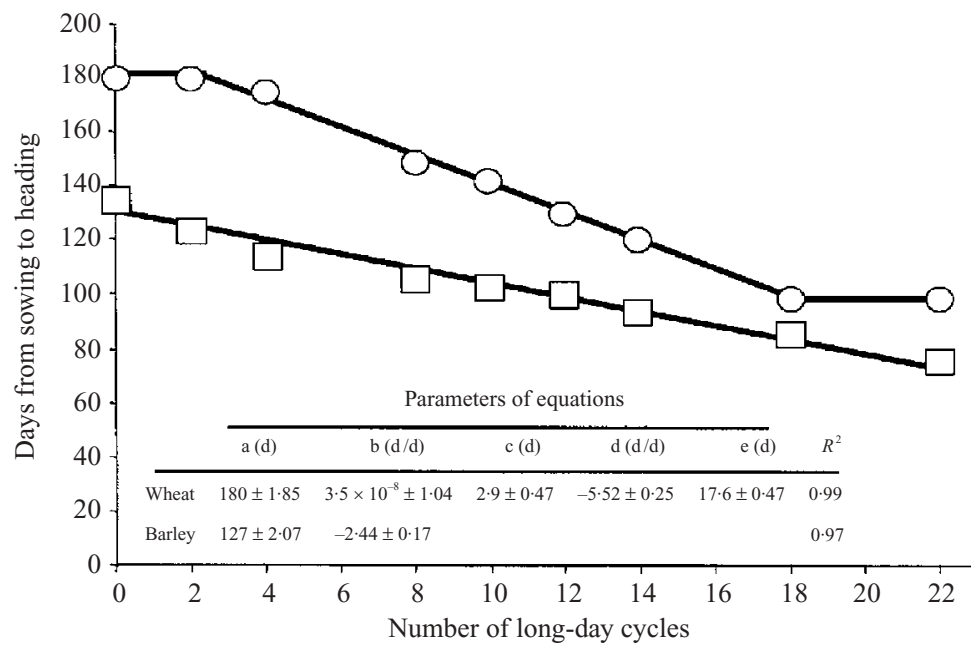

Fig. 2. Relationship between time to heading and the length of the exposure to long-day cycles in wheat (circles) and barley (squares). Solid lines were fitted by linear (barley) or tri-linear models (wheat). Parameters of the regression are shown in the inset table.

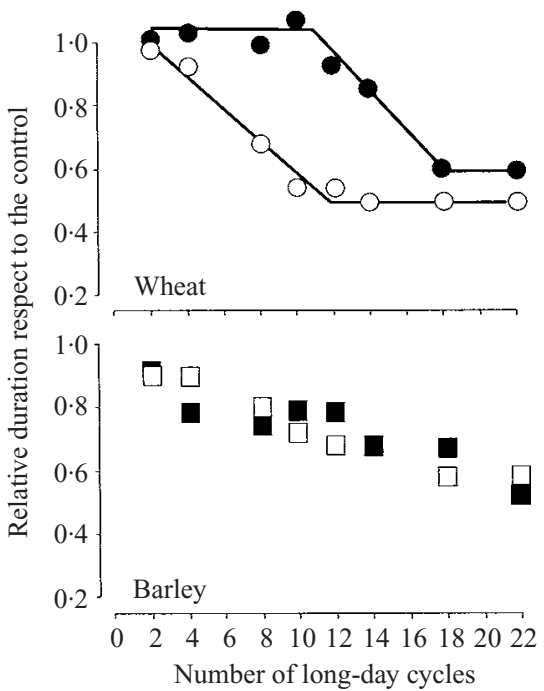

Fig. 3. Days from sowing to maximum number of primordia or terminal spikelet initiation for wheat and barley, respectively (open symbols) and from then to heading (closed symbols) $v$. the length of the exposure to long-day cycles in wheat (circles) and barley (squares). Solid lines were fitted by linear regression.

phase corresponded to an exposure taking place very close or before the onset of the phase itself, i.e. a response to the memory photoperiod. Although the response of the initial phase from sowing to terminal spikelet initiation seemed to be saturated after the exposure of 10 long-day cycles in UQ189 wheat, the length of the TS-H phase was consistently reduced until saturation 8 days later (Fig. 3). Similarly the sowing-maximum number of primordia phase in barley stopped its response after 18 days of exposure to long photoperiod while the later reproductive phase until heading continued with the reduction even when the previous phase had already been saturated (Fig. 3).

Final leaf number (FLN) initiated on the main stem in wheat decreased linearly as the number of long-day cycles increased from 0 to 12 days. Beyond 12 days exposure to long days no further reduction in FLN was observed. In Arapiles barley there was no further reduction in FLN with exposure to more than 4 long-days (Table 1).

A clear relationship was established between the maximum number of spikelet primordia per spike and the duration of the spikelet initiation phase (from collar to terminal spikelet appearance or awn initiation). The determination coefficients were high and significant in both wheat $\left(R^{2}=0.96, P<0.01\right.$, $n=9)$ and barley $\left(R^{2}=0 \cdot 84, P<0 \cdot 01, n=9\right)$. Barley showed a faster rate of spikelet initiation $(0 \cdot 30 \pm 0 \cdot 05$ spikelet primordia/day) than wheat $(0 \cdot 23 \pm 0.02$ spikelet primordia/day), and therefore reached a far higher number of spikelets initiated at awn initiation than wheat at terminal spikelet appearance.

Leaf primordium initiation, calculated by dividing the FLN by the time from S to CL, showed little variation and there was no response to the duration of the photoperiod treatments. Averaging across treatments plastochron was 2.5 and 1.9 days per leaf initiated in the apex for wheat and barley, respectively. Similarly the rate of spikelet initiation in wheat 


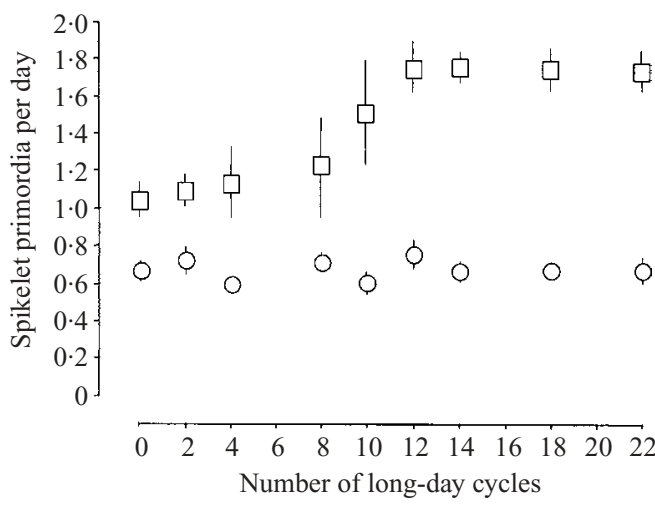

Fig. 4. Relationship between the rate of spikelet initiation and the length of the exposure to long-day cycles in wheat (circles) and barley (squares). The rates were calculated by regression of accumulated number of primordia and time from collar to terminal spikelet appearance (wheat) or to awn initiation (barley), when the maximum number of spikelet primordia was reached. Bars show the standard error of the rate.

did not show significant variation when plants were retained in long photoperiods for different periods of time. Barley showed a faster rate of spikelet initiation than wheat across all treatments, but also a response to the length of exposure to photoperiod (Fig. 4). Spikelet initiation rates for Arapiles barley responded to the initial increases in length of exposures and saturated its response with exposures of around 12 days (imposed from 15 days after seedling emergence), with no further increases in rate of spikelet initiation with longer exposures (Fig. 4).

Changes in final leaf number were smaller than changes to heading time and therefore the rhythm with which the leaves appeared was also affected by the treatments imposed 2 weeks after seedling emergence. The analysis of the residuals of the relationship between leaves' emergence and time revealed that a linear model was adequate to fit the relationships for those plants that were retained in long photoperiods from 14 to 22 days for UQ189 wheat and 12 and 22 days for Arapiles barley. For the rest of the treatments, lack of linearity was apparent (see extreme treatments as example in Fig. 5, left panels), and a bi-linear model was used to fit the relationship between leaf emergence and time (Table 1). In these cases, the number of leaves appeared on the main stem when the break in the rate of leaf emergence occurred was between 8 and 10 in wheat and between 6 and 8 in barley. In all cases the rate of leaf emergence for those leaves emerged before the break in the slope was faster than those leaves that emerged after that point (Table 1). Averaging over treatments, within each wheat and barley genotype, the phyllochron for those leaves that emerged before the break 

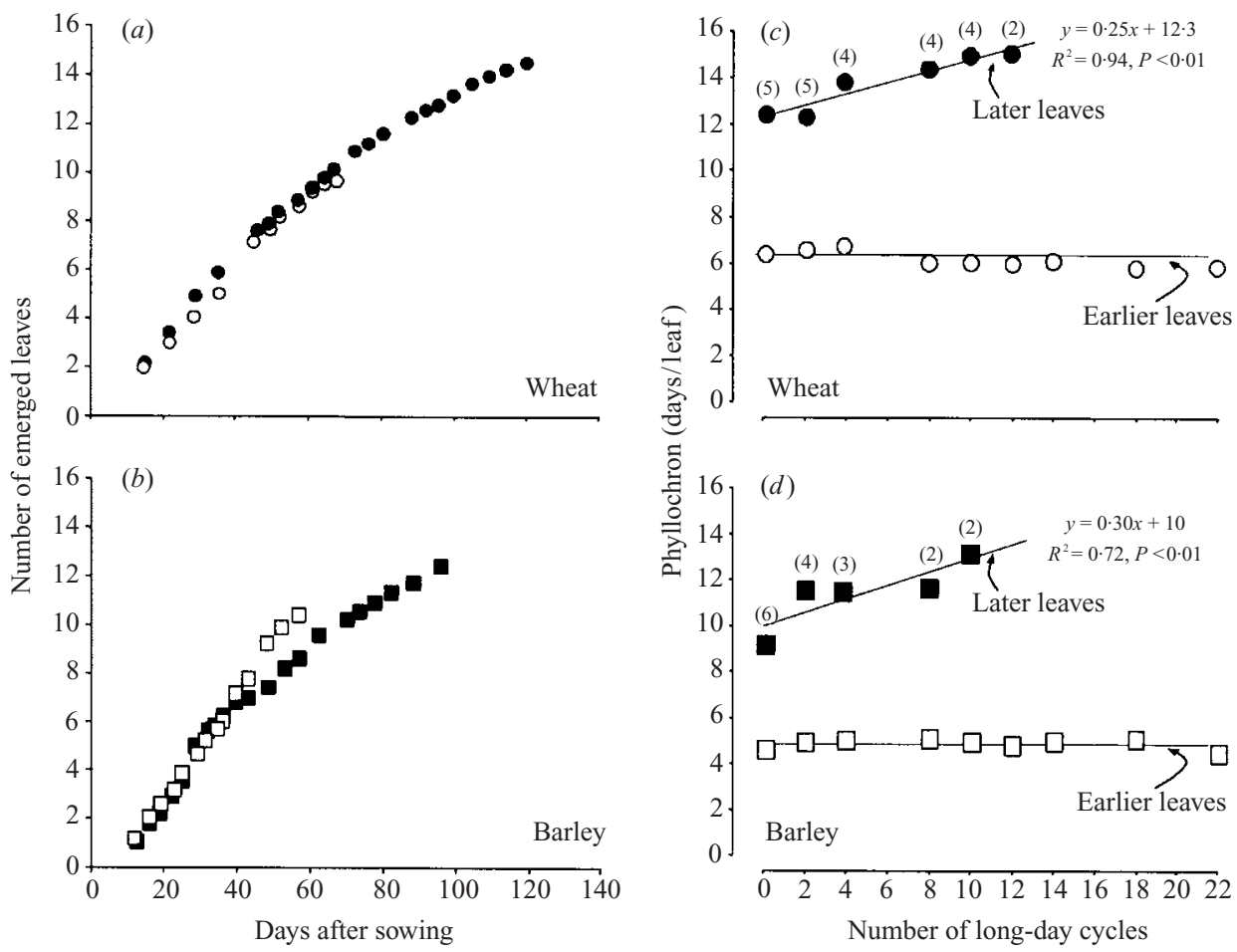

Fig. 5. Relationship between the cumulative number of leaves on the main stem (Haun stage) and time from sowing for wheat $(a)$ and barley $(b)$ plants being exposed to 0 (always under 9-h photoperiod, closed symbols) or 22 long days ( 2 weeks under short photoperiod followed by 3 weeks of 19-h photoperiod days and then back to 9 h, open symbols). Calculated values of phyllochron for leaves emerged before (earlier leaves) and after (later leaves) the break in rate of leaf emergence on the main stem plotted against the length of exposure to long-day cycles in wheat $(c)$ and barley $(d)$. Numbers between parentheses indicate the number of leaves to have emerged after the switch from fast to slow phyllochron. Note that plants exposed to more than 10-12 cycles only have a single, relatively short phyllochron as their Haun stages were linearly related to time.

point was $6 \cdot 2$ and 4.9 days/leaf for wheat and barley, respectively (Fig. 5, right panels). No significant differences were found among photoperiod treatments for those leaves that emerged before the break point (i.e. earlier leaves, Table 1), however, the phyllochron of leaves that emerged after the break (i.e. later leaves) increased with the increasing long photoperiod cycles. In spite of the increased phyllochron of later leaves, the number of leaves to emerge with a longer phyllochron (later leaves) was reduced as plants were retained in the long photoperiod for a long time, counterbalancing any possible delayed effect exerted by a slower rate of leaf emergence of the later formed leaves (Fig. 5, right panels).

\section{DISCUSSION}

Most of the literature on cereal responsiveness to photoperiod describes the quantitative response to the daylength to which the plants are exposed throughout its growing season (e.g. see reviews by
Slafer \& Rawson 1994; Miralles \& Slafer 1999; García del Moral et al. 2002). This sort of description is essential in order to understand the general behaviour in flowering conferring adaptation abilities (Slafer \& Whitechurch 2001) and to be able to describe differences among genotypes, sowing dates and/or locations. There has been an increasing interest in understanding the responsiveness to photoperiod throughout different phenophases (Slafer \& Rawson 1994), as they may not only have academic interest but also utility in breeding for further yield increases (Slafer et al. 2001). One of the unresolved questions in the responses of different phases is based on the independence of these responses to those taking place earlier. One alternative (see Slafer \& Rawson 1994; Miralles \& Richards 2000) for the existence of an independent response of different phases is the existence of a continuous sensing of the photoperiod environment and a continuous capacity to respond to this perception. A general conclusion from the present paper is that both wheat and barley seemed to 
respond quantitatively to the number of long-day cycles they were exposed to. This implies the ability to perceive continuously the photoperiod under which they are grown, accelerating and slowing down their developmental rates accordingly.

In addition, the wheat cultivar showed a requirement of approximately three cycles of long photoperiod to be able to produce a significant response in time to heading, which coincides with the finding by Slafer \& Rawson (1995) with a different cultivar (Condor). This requirement seems not to be associated with the existence of a juvenile phase in wheat as (i) treatments were imposed well after seedling emergence in the present study and (ii) the same requirement of few cycles of long photoperiod before expressing any response was evident in the study by Slafer \& Rawson (1994) when the treatments were applied at seedling emergence and later during the most sensitive period to long days. Besides that, there seems to be no evidence of wheat possessing such a juvenile period (Hay \& Kirby 1991). Perhaps the requirement of several cycles of long photoperiod before a response may be triggered plays a similar ecological role to that of a short juvenile period. Interestingly, the barley cultivar used in the present study was responsive to the minimum length of exposure, although barley is usually regarded as a plant possessing a juvenile period of insensitivity to daylength immediately after seedling emergence (Roberts et al. 1988).

The continuous sensing of and response to cycles of long photoperiod involved the responses throughout different phases. The fact that the phase of sowingterminal spikelet appearance seemed more sensitive than the stem elongation phase in the wheat used in the present study does not have to be taken as a fact. Extended photoperiod cycles were only imposed before the appearance of the terminal spikelet and therefore all the response in stem elongation phase was due to the 'memory' effect of photoperiod (Slafer \& Rawson 1994), which is frequently smaller than the effects produced by the direct exposition (Miralles \& Richards 2000). The magnitude of the memory response in barley was even greater than that of wheat as the overall response of both phases (pre- and postawn initiation) in barley were similar, but the pre-awn initiation phase was exposed to direct effects and the later phase only responded to the memory effects.

Interestingly, at least part of the memory response to photoperiod of the stem elongation phase in the case of wheat was related to the fact that the preterminal spikelet appearance phase saturated its response well in advance of reaching the stage. This can be interpreted as the plant being committed to the terminal spikelet appearance (and to stop producing spikelet primordia) before the stage could be recognized and consequently the stimulus produced by the sensing of further long days translated in a memory response thereafter. However, this model may not be general as in the case of barley it seemed that the perception of photoperiod was simultaneously producing direct responses by the pre-awn initiation phase and memory responses by the stem elongation phase.

In general terms the results of the present study are consistent with the literature in that the response to photoperiod, for the time from sowing to the onset of stem elongation, was associated with changes in final leaf number and in spikelets per spike (Rawson 1971; Halloran 1977; Kirby 1992; Rawson \& Richards 1993; Slafer \& Rawson 1994, 1996). However, much of the strong relationship between length of the period to maximum number of (leaf and spikelet) primordia and the number at the onset of stem elongation are based on the fact that photoperiod has generally a small (if any) effect on the rate of primordia initiation (e.g. Miglietta 1991; Rawson 1993; Evans \& Blundell 1994). This was also the case in the present study for leaf initiation in both cereals, and for spikelet initiation in wheat. However, barley showed a clear trend to increase the rate of spikelet initiation when the exposure to long photoperiod was extended, which means that if the stimulus is strong enough, the rate of spikelet initiation may also be responsive to the acceleration of development and then the changes in length may be reflected by a much smaller change in maximum number of spikelet initiated.

As the response in duration to heading exceeded that of the final leaf number, and that the stem elongation phase responded to memory effects of photoperiod, the phyllochron of both cereals was responsive to the treatments accelerating the average phyllochron when exposed to longer periods of long days. The general response of this nature to the actual length of the day has been previously reported (Rawson 1993; Cao \& Moss 1994) as well as the fact that the response in average phyllochron was due to a switch from bi-linear to linear models of leaf number $v$. time when the conditions were increasingly inductive, with the phyllochron of the initial (6-8) leaves being similar for all treatments (within each species), and from then on increased (Jamieson et al. 1995; Slafer \& Rawson 1997; Miralles \& Richards 2000). Consequently, both in the present study and in those where treatments are the daylengths imposed throughout, the higher the final leaf number the higher the average phyllochron, due to an increased number of leaves to appear after the switch (approximately between leaves 6 and 8 ).

This work was supported by IFS (International Foundation for Science) Grant C/2804-1, UBACyT (University of Buenos Aires) and CONICET. We are grateful to the technical staff of the Canberra phytotron for the assistance in this study. 


\section{REFERENCES}

Allison, C. J. \& Daynard, T. B. (1976). Effects of photoperiod on development and number of spikelets of a temperate and some low-latitude wheats. Annals of Applied Biology 83, 93-102.

CAo, W. \& Moss, D. N. (1994). Sensitivity of winter wheat phyllochron to environmental changes. Agronomy Journal 86, 63-66.

Ellis, R. H., Collinson, S. T., Hudson, D. \& Patefield, W. M. (1992). The analysis of reciprocal transfer experiments to estimate the durations of the photoperiodsensitive and photoperiod-insensitive phases of plant development: an example in soya bean. Annals of Botany 70, 87-92.

Evans, L. T. \& Blundell, C. (1994). Some aspects of photoperiodism in wheat and its wild relatives. Australian Journal of Plant Physiology 21, 551-562.

FISCHER, R. A. (1996). Wheat physiology at CIMMYT and raising the yield plateau. In Increasing Yield Potential in Wheat: Breaking the Barriers (Eds M. P. Reynolds, S. Rajaram \& A. McNab), pp. 195-202. Mexico: CIMMYT.

García del Moral, L., Miralles, D. J. \& Slafer, G. A. (2002). Phasic and foliar development. In Barley Science: Recent Advances from Molecular Biology to Agronomy of Yield and Quality (Eds G. A. Slafer, J. L. Molina Cano, R. Savin, J. L. Araus \& I. Romagosa), pp. 243-268. New York: Food Product Press.

Halloran, G. M. (1977). Developmental basis of maturity differences in spring wheat. Agronomy Journal 69, 899-902.

Haun, J. R. (1973). Visual quantification of wheat development. Agronomy Journal 65, 116-119.

HAY, R. K. M. (1986). Sowing date and the relationships between plant and apex development in winter cereals. Field Crops Research 14, 321-337.

Hay, R. K. M. \& Kirby, E. J. M. (1991). Convergence and synchrony - a review of the coordination of development in wheat. Australian Journal of Agricultural Research 42, 661-700.

Jamieson, P. D., Brooking, I. R., Porter, J. R. \& WILSON, D. R. (1995). Prediction of leaf appearance in wheat: a question of temperature. Field Crops Research 41, 35-44.

Kernich, G. C., Halloran, G. M. \& Flood, R. G. (1997). Variation in duration of preanthesis phases of development in barley (Hordeum vulgare). Australian Journal of Agricultural Research 48, 59-66.

Kirby, E. J. M. (1991). Cereal development in Mediterranean environments. In Improvement and Management of Winter Cereals under Temperature, Drought and Salinity Stresses (Eds E. Acevedo, E. Fereres, C. Gimenez \& J. P. Srivastava), pp. 63-83. Madrid: Instituto Nacional de Investigaciones Agrarias.

Kirby, E. J. M. (1992). A field study of the number of main shoot leaves in wheat in relation to vernalization and photoperiod. Journal of Agricultural Science, Cambridge 118, 271-278.

Miglietta, F. (1991). Simulation of wheat ontogenesis. II. Predicting dates of ear emergence and main stem final leaf number. Climate Research 1, 151-160.

Miralles, D. J. \& Richards, R. A. (2000). Responses of leaf and tiller emergence and primordium initiation in wheat and barley to interchanged photoperiod. Annals of Botany 85, 655-663.

Miralles, D. J. \& Slafer, G. A. (1999). Wheat development. In Wheat: Ecology and Physiology of Yield Determination (Eds E. H. Satorre \& G. A. Slafer), pp. 13-43. New York: Food Product Press.

Miralles, D. F., Richards, R. A. \& Slafer, G. A. (2000). Duration of the stem elongation period influences the number of fertile florets in wheat and barley. Australian Journal of Plant Physiology 27, 931-940.

Porter, J. R. \& Delecolle, R. (1988). Interaction of temperature with other environmental factors in controlling the development of plants. In Plants and Temperature (Eds S. P. Long \& F. I. Woodward), pp. 133-156. Cambridge: The Company of Biologists Limited.

Rahman, M. S. \& Wilson, J. H. (1977). Determination of spikelet number in wheat. I. The effect of varying photoperiod on ear development. Australian Journal of Agricultural Research 28, 565-574.

Rawson, H. M. (1970). Spikelet number, its control and relation to yield per ear in wheat. Australian Journal of Biological Sciences 23, 1-15.

Rawson, H. M. (1971). An upper limit for spikelet number per ear in wheat as controlled by photoperiod. Australian Journal of Agricultural Research 22, 537-546.

Rawson, H. M. (1993). Radiation effects on rate of development in wheat grown under different photoperiods and high and low temperatures. Australian Journal of Plant Physiology 20, 719-727.

Rawson, H. M. \& Richards, R. A. (1993). Effects of high temperature and photoperiod on floral development in wheat isolines differing in vernalisation and photoperiod genes. Field Crops Research 32, 181-192.

Ritchie, J. T. (1991). Wheat phasic development. In Modelling Plant and Soil Systems (Eds J. Hanks \& J. T. Ritchie), pp. 31-54. Madison, WI: American Society of Agronomy.

Roberts, E. H., Summerfield, R. J., Cooper, J. P. \& Ellis, R. H. (1988). Environmental control of flowering in barley (Hordeum vulgare L.). I. Photoperiod limits to long-day responses, photoperiod-insensitive phases and effects of low-temperature and short-day vernalization. Annals of Botany 62, 127-144.

Slafer, G. A. \& Rawson, H. (1994). Sensitivity of wheat phasic development to major environmental factors: a reexamination of some assumptions made by physiologist and modellers. Australian Journal of Plant Physiology 21, 393-426.

Slafer, G. A. \& Rawson, H. M. (1995). Development in wheat as affected by timing and length of exposure to long photoperiod. Journal of Experimental Botany 46, 1877-1886.

Slafer, G. A. \& Rawson, H. M. (1996) Responses to photoperiod change with phenophase and temperature during wheat development. Field Crops Research 46, 1-13.

Slafer, G. A. \& Rawson, H. M. (1997). Phyllochron in wheat as affected by photoperiod under two temperature regimes. Australian Journal of Plant Physiology 24, $151-158$.

Slafer, G. A. \& Whitechurch, E. M. (2001). Manipulating wheat development to improve adaptation and to search for alternative opportunities to increase yield potential. 
In Application of Physiology in Wheat Breeding (Eds M. P. Reynolds, J. I. Ortiz-Monasterio \& A. McNab), pp. 160-170. Mexico: CIMMYT.

Slafer, G. A., Calderini, D. F. \& Miralles, D. J. (1996). Yield components and compensation in wheat: opportunities for further increasing yield potential. In Increasing Yield Potential in Wheat: Breaking the Barriers (Eds M. P. Reynolds, S. Rajaram \& A. McNab), pp. 101-133. Mexico: CIMMYT.
Slafer, G. A., Abeledo, L. G., Miralles, D. J., González, F. G. \& Whitechurch, E. M. (2001). Photoperiod sensitivity during stem elongation as an avenue to rise potential yield in wheat. Euphytica 119, 191-197.

Stapper, M. \& Fischer, R. A. (1990). Genotype, sowing date and planting spacing influence on high yielding irrigated wheat in southern New South Wales. I. Phasic development, canopy growth and spike production. Australian Journal of Agricultural Research 41, 997-1019. 